\title{
The place of transvaginal ultrasonography saline infusion sonohysterography and hysteroscopy in the diagnosis of abnormal uterin bleedings
}

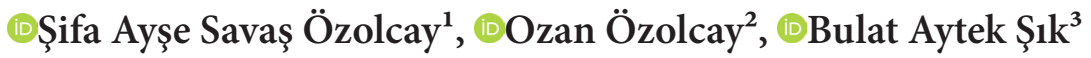 \\ ${ }^{1}$ İstanbul Bakırköy Dr. Sadi Konuk Education and Research Hospital, Department of Gynecology and Obstetrics, İstanbul, Turkey \\ ${ }^{2}$ İstanbul IVF Centre, Department of Gynecology and Obstetrics, İstanbul, Turkey \\ ${ }^{3}$ İstanbul Aydın University, School of Medicine, Department of Gynecology and Obstetrics, İstanbul, Turkey
}

Cite this article as: Savaş Özolcay ŞA, Özolcay O, Şık BA. The place of transvaginal ultrasonography saline infusion sonohysterography and hysteroscopy in the diagnosis of abnormal uterin bleedings. J Health Sci Med 2021; 4(2): 154-159.

\begin{abstract}
Aim: To establish the accuracy of transvaginal ultrasonography, saline infusion sonohysterography and hysteroscopy in diagnosing uterine pathology in patients with abnormal uterine bleeding.

Material and Method: In our study, Transvaginal ultrasonography (TVUSG), saline infusion sonohysterography (SIS) and hysteroscopy were applied to 60 patients in the reproductive period, who did not use any contraception method other than condom, who did not have chronic and systemic diseases, who applied to our clinic with abnormal uterine bleeding. Dilatation \& Curettage (D\&C) was applied to all patients after the procedure. Histopathology results obtained with D\&C were compared with those obtained with TVUSG, SIS and hysteroscopy.

Results: Histopathologically, 28 patients (46.7\%) endometrial polyp, 4 patients (6.7\%) submucous myoma, 10 patients (16.7\%) endometrial hyperplasia was in the form of endometrial changes due to cycle irregularities in 18 patients (30\%). The sensitivity, specificity, positive and negative predictive values for detection of intracavitary pathology by transvaginal sonography were $71.42 \%, 77.78 \%, 88.23 \%, 83.85 \%$. The values determined by saline infusion sonohysterography were respectively $88.89 \%$, $90.48 \%, 80.00 \%, 95.0 \%$ and by hysteroscopy were respectively $100 \%, 90.00 \%, 95,24 \%, 100 \%$.

Conclusion: TVUSG and SIS is a cheaper, easier and highly diagnostic value procedure for detecting endometrial pathologies such as endometrial polyps and submucous myomas. However, due to the high diagnostic values, low complication rates, direct biopsy and simultaneous treatment, we believe that hysteroscopy will maintain it's 'gold standard' feature in the diagnosis and treatment of endometrial pathologies for many years.
\end{abstract}

Keywords: Abnormal uterine bleeding, hysteroscopy, endometrial polyp, saline infusion sonohystygraphy

\section{INTRODUCTION}

Most women experience menstrual cycle irregularities at some part of their lives. Abnormal uterine bleeding (AUB), which is one of those kind irregularities, is up to one third of reason for admission to gynecology outpatient clinic throughout life and postmenopausal period. The main causes of abnormal uterine bleeding are classified as; polyp, adenomyosis, leiomyoma, malignancy and hyperplasia, coagulopathy, ovulatory dysfunction, endometrial causes,iatrogenic and those not yet classified (1). The diagnosis of space-occupying lesions in the endometrial cavity with transvaginal ultrasonography (USG) and saline infusion hydrosonography (SIS) has been used

safely for many years. However, endometrial sampling is an important diagnostic method in the diagnosis of endometrial pathologies (2). Dilatation/curettage (D\&C) procedure, was first applied by Recaimer in 1843, has been used in the detection of endometrial pathologies and accepted as a gold standard (3). First the cervix is dilated, then all parts of the endometrium from fundus to internal os are curetted, it is an invasive method with a high risk of complication (4). Hysteroscopy (H/S) can be performed in an outpatient examination environment because of hysteroscopy is a low cost, effective and reliable method that does not require anesthesia (5). SIS, 
is another diagnostic and treatment method which can be used in abnormal uterine bleeding and infertility. SIS, can be used as providing distension of the endometrial cavity with sterile saline and visualized the uterine cavity with ultrasonography $(6,7)$.

In our study, the patients who had complaint of abnormal uterine bleeding in their reproductive and perimenopausal period were detected with transvaginal ultrasonography (TVUSG), saline infusion sonohysterography (SIS), Hysteroscopy and Dilatation \& Curettage (D\&C) as a diagnostic methods and comparing our visual diagnosis with the histopathological diagnosis of tissue obtained by D\&C, according to literature information to reveal the accuracy and reliability of these diagnostic methods.

\section{MATERIAL AND METHOD}

Patient in this study was selected between June 2008 and November 2009, in İstanbul Bakırköy Dr. Sadi Konuk Education and Research Hospital Gynecology and Obstetrics Clinic, a total of 74 patients of childbearing age who presented with the disease of abnormal uterine bleeding complaint were included. The study was approved by İstanbul Bakırköy Dr. Sadi Konuk Education and Research Hospital Ethics Committee (date: June 01, 2008; Approval number: 303). All procedures were performed adhered to the ethical rules and the Helsinki Declaration of principles.

Patients who has chronic and systemic disease, continuous use of medication, take hormone replacement therapy, use intrauterine device or using contraceptive medication, pregnant or genital tract infection were not included in the study. The study was carried out in the gynecology service of the hospital, following the approval of the hospital training planning and ethics committee. All patients included the study were informed about the procedure which performed and their complications, and bill of consent was signed. Detailed gynecological anamnesis of all patients were taken, their systemic and pelvic examinations done. TVUSG, SIS, H/S and D\&C respectively performed to all patients, obtaining material was send to histopathological evaluation and results were recorded. 14 patient was excluded from the study because they did not accept the intervention in different part of the stages. Study completed with 60 patients.

Transvaginal ultrasonography was performed by single observer using General Electric Logic 200 brand 3.5 $\mathrm{mHz}$ vaginal probe. Cervix, cervical canal, myometrium and ovaries were examined in both sagittal and coronal planes. After evaluating the endometrial morphological pattern and endometrial junction, endometrial thickness measured from the outside to the outside in the thickest place (in the longitudinal plane). SIS process performed early or mid proliferative phase. While the patients were in dorsolithotomy position, a speculum was inserted into their vagina. After the cervix was made visible, wipe it with an antiseptic solution (Povidone iodine) cleaned. The cervix is fixed with a teneculum if necessary and $8 \mathrm{fr}$ catheter was placed in the uterine cavity. After fixing the catheter with forceps, the speculum was removed and a transvaginal ultrasound probe was placed in to the vagina. A 20-50 cc syringes was attached to the tip of the catheter, saline is given slowly into the cavity until sufficient distension was achieved and the findings were recorded. Office hysteroscopy was performed by $3 \mathrm{~mm}$ hysteroscope (Karl Storz, Tutlingen, Germany). Office hysteroscopy was performed in the dorsal lithotomy position while the bladder was empty. The procedure was performed after cleaning the External genitals, vagina and cervix with antiseptic solution povidone-iodine. Uterine distention was carried out using saline. After hysteroscopy D\&C performed for all patients. The material taken was kept in alcohol and sent to the pathology laboratory. Cases in which sufficient material cannot be obtained, was evaluated as cases with no pathology detected. No complications occurred due to the procedures performed. By comparing our visual diagnosis with the histopathological diagnosis of tissue obtained by dilatation curettage, we tried to reveal the accuracy and reliability of these diagnostic methods in the light of the literature.

\section{Statistical Analysis}

While evaluating the findings obtained in the study, NCSS for statistical analysis 2007 \& PASS 2008 Statistical Software (Utah, USA) program was used. While evaluating the study data after $\mathrm{H} / \mathrm{S}$ in addition to descriptive statistical methods (Mean, Standard deviation) it was handled as biopsy results are the gold standard in comparison of qualitative data. According to TVUSG, SIS and H/S results, diagnostic screening tests for each test separate sensitivity, specificity, positive predictive value (PPV), negative predictive value (NPV), and kappa scores were calculated. Statistical significance was evaluated at the $\mathrm{p}<0.05$ level.

\section{RESULTS}

Sixty patients with abnormal uterine bleeding were included in the study. All patients consisted of gave birth and fertile women. According to SIS results; $33.3 \%$ of patient had normal histology, $16.7 \%$ hyperplasia, $46.7 \%$ polyps and 3.3\% myoma. H/S results; normal histology in $30 \%$, hyperplasia in $13.3 \%$, polyp in $50.0 \%$ and myoma in $6.7 \%$ of the patient seen. The clinical and demographic characteristics of the patients are given in Table $\mathbf{1}$.

The histopathological distribution of patients who underwent TVUSG, SIS, and H/S are given in Table 2. 
Table 1. Clinical and demographic characteristics of the patients

\begin{tabular}{|c|c|c|c|c|}
\hline & \multicolumn{2}{|c|}{ Min-Max } & \multicolumn{2}{|c|}{ Ort \pm SD (Median) } \\
\hline Age & \multicolumn{2}{|c|}{$32-45$} & \multicolumn{2}{|c|}{$39.70 \pm 3.04$} \\
\hline BMI & \multicolumn{2}{|c|}{$17.36 \pm 29.42$} & \multicolumn{2}{|c|}{$23.43 \pm 4.72$} \\
\hline Gravida & \multicolumn{2}{|c|}{$2-7$} & \multicolumn{2}{|c|}{$4.0 \pm 1.5$} \\
\hline Parity & \multicolumn{2}{|c|}{$1-6$} & \multicolumn{2}{|c|}{$2.95 \pm 1.05$} \\
\hline Abortus & \multicolumn{2}{|c|}{$1-8$} & \multicolumn{2}{|c|}{$4.02 \pm 2.86$} \\
\hline Histopathological diagnosis & TVUSG n (\%) & SIS n (\%) & H/S n (\%) & Toplam n:60 \\
\hline Normal & $16(26.7 \%)$ & $20(33.3 \%)$ & $18(30 \%)$ & $18(30.0 \%)$ \\
\hline Hyperplasia & $18(30.0 \%)$ & $10(16.7 \%)$ & $8(13.3 \%)$ & $10(16.7 \%)$ \\
\hline Polyp & $22(36.7 \%)$ & $28(46.7 \%)$ & $30(50 \%)$ & $28(46.7 \%)$ \\
\hline Myoma & $4(6.7 \%)$ & $2(3.3 \%)$ & $4(6.7 \%)$ & $4(6.7 \%)$ \\
\hline
\end{tabular}

Table 2. Histopathological distribution of patients who underwent TVUSG, SIS, and H/S

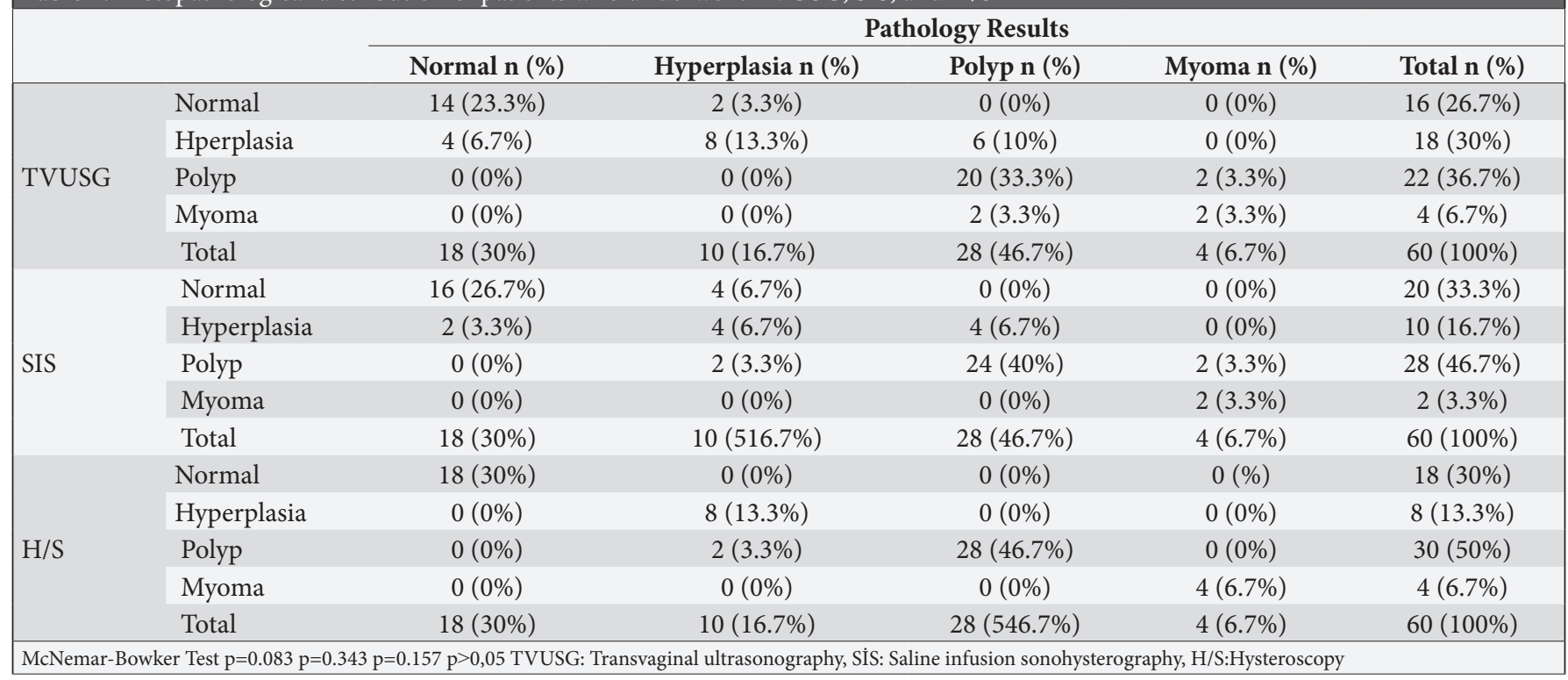

When looking at the efficiency of TVUSG in the diagnosis of endometrial pathologies, sensitivity is $71.42 \%$; specificity is $77.78 \%$, positive predictive value is $88.23 \%$, and negative predictive value is $53.85 \%$. In endometrial hyperplasia, sensitivity is $80 \%$, specificity is $80 \%$, in polyps sensitivity is $71.43 \%$ and specificity was evaluated as $93.75 \%$. Sensitivity is $50 \%$, specificity was determined as $96.4 \%$ in endometrial myomas. When looking at the effectiveness of SIS in the diagnosis of endometrial pathologies, the sensitivity is $88.89 \%$, specificity $90.48 \%$, positive predictive value $80.00 \%$ and the negative predictive value is $95.0 \%$. In endometrial hyperplasia; It was evaluated as sensitivity $40 \%$ and specificity $88 \%$. In polyps; sensitivity $85.71 \%$, specificity $87.50 \%$. In endometrial myomas; sensitivity was $50 \%$ and specificity was $100 \%$. Considering the effectiveness of hysteroscopy in the diagnosis of endometrial pathologies, sensitivity $100 \%$; specificity is $90 \%$, positive predictive value is $95.24 \%$, and negative predictive value is $100 \%$. In endometrial hyperplasia, sensitivity is $80 \%$, specificity is $100 \%$, and in polyps sensitivity is $100 \%$ and specificity was evaluated as $93.75 \%$. Sensitivity and specificity was determined as $100 \%$ in endometrial myomas. Diagnostic accuracy values of TVUSG, SIS, $\mathrm{H} / \mathrm{S}$ is given in Table 3 .

\begin{tabular}{|lcccc|}
\hline \multicolumn{5}{|c|}{ Table 3. Diagnostic accuracy values of TVUSG, SIS, H/S } \\
\hline & Sensitivity & Specificity & $\begin{array}{c}\text { Positive } \\
\text { predictive } \\
\text { value }\end{array}$ & $\begin{array}{c}\text { Negative } \\
\text { predictive } \\
\text { value }\end{array}$ \\
\hline TVUSG & & & & \\
Normal & 77.78 & 95.24 & 87.50 & 90.91 \\
\hline Hyperplasia & 80.00 & 80.00 & 44.44 & 95.24 \\
Polyp & 71.43 & 93.75 & 90.91 & 78.95 \\
Myoma & 50.00 & 96.43 & 50.00 & 96.43 \\
SíS & & & & \\
\hline Normal & 88.89 & 90.48 & 80.00 & 95.00 \\
Hyperplasia & 40.00 & 88.00 & 40.00 & 88.00 \\
\hline $\begin{array}{l}\text { Polyp } \\
\text { Myoma }\end{array}$ & 85.71 & 87.50 & 85.71 & 87.50 \\
H/S & 50.00 & 100.00 & 100.00 & 96.55 \\
$\begin{array}{l}\text { Normal } \\
\text { Hyperplasia }\end{array}$ & 100.00 & 100.00 & 100.00 & 100.00 \\
\hline $\begin{array}{l}\text { Polyp } \\
\text { Myoma }\end{array}$ & 100.00 & 100.00 & 100.00 & 96.15 \\
\hline $\begin{array}{l}\text { TVUSG: Transvaginal ultrasonography, SIS: Saline infusion sonohisterography, } \\
\text { H/S:Hysteroscopy }\end{array}$ & 100.00 & 100.00 & 100.00 & 100.00 \\
\hline
\end{tabular}




\section{DISCUSSION}

Irregularities in gonadotropin hormones in women and hyperandrogenemia caused by hyperinsulinemia ia main reason in anovulation. In addition, androgens are converted to estrogen in adipose tissue and increased estrogens have a proliferative and hyperplasic effect on the endometrium. All of these factors together can cause abnormal uterine bleeding in women (8). The estrogen hormone has a stimulating effect on the endometrium. Continuous estrogen stimulation in the endometrium causes many gynecological problems. Estrogen plays a role in the etiopathogenesis of endometrial polyp, which is one of the causes of abnormal uterine bleeding. Increasing estrogens trigger proliferative, hyperplasic and eventually endometrial cancer pathways for the endometrium. Estrogen is one of the most important factors involved in the formation of endometrial cancer precursors such as endometrial cancer and hyperplasia. (9-12) Abnormal uterine bleeding (AUB) is one of the most common reasons for referrals to gynecology outpatient clinics. This clinical situation, which is often an indicator of a pathology in the reproductive system, sometimes it can be a symptom of disorders of other systems (13).

In the evaluation of the uterine cavity, TVUSG can directly detect abnormal uterine structures or it can be used for imaging or detecting anomalies. In general for determining endometrial pathologies, TVUSG sensitivity is reported between $46-100 \%$ (14). TVUSG can detect submucous myomas with a sensitivity of 21$100 \%$, specificity range is between $33-100 \%$. Sensitivity for endometrial hyperplasia and cancer is between 33\% 100 , specificity is between $79-99 \%$ (14). Endometrial pathologies of TVUSG, has low diagnostic value particularly in evaluating focal abnormalities, but it has been reported that, this could be the first step method which will reduce the need for invasive procedures (15). In the study of Dijkhuizen et al. (16) in 50 premenopausal women's hysterectomy specimens compared the TVUSG and SIS findings with the pathological examination findings, they detected 13 myomas and 10 polyps, detection of polyps with TVUSG has sensitivity $40 \%$, specificity $100 \%$, positive predictive value (PPD) $100 \%$, negative predictive value (NPD) reported as $87 \%$. Direct detection of endometrial polyps has a low sensitivity with TVUS. In our study, the diagnosis of endometrial pathologies with TVUSG has a sensitivity of $71.42 \%$, and a specificity of $77.78 \%$. Sensitivity and specificity of TVUSG in the diagnosis of submucous myoma $96.43 \%$; sensitivity for endometrial polyp $71.43 \%$, specificity $93.75 \%$. in endometrial hyperplasia, the sensitivity is $80.0 \%$ and the specificity is $80.0 \%$, similar rates to the literature has been found.
In determining focal intrauterine pathologies SIS has a prominent advantage over TVUSG. It gives a higher diagnostic accuracy rate in detecting intracavitary lesions. Sensitivity and specificity of TVUSG in the diagnosis of intracavitary lesions reported by Williams et al. (17) as $67 \%$ and $93 \%$, it was emphasized by De Vries et al (14) that the same rates were $60 \%$ and $93 \%$ with TVUSG respectively. As a result, SIS is superior to TVUSG in recognizing intracavitary pathologies, however It is found that SIS is insufficient to recognize endometrial pathologies such as hyperplasia other than polyp and myoma (18). In our study, the efficiancy of SIS in determining intracavitary lesions has asensitivity of $88.89 \%$ and specificity of $90.48 \%$. Determination of endometrial polyps sensitivity $85.71 \%$ specificity $87.50 \%$, in submucous myomas sensitivity $50 \%$, specificity $100 \%$. In endometrial hyperplasia, sensitivity $40 \%$ specificity $88 \%$. These results were also found similar to the literature.

As a sensitive method hysteroscopy is and highly used in the detection of endometrial pathologies in the current literature. In 419 postmenopausal women Garutti et al. (19) performed hysteroscopy for determining endometrial pathologies, in their study sensitivity $96.5 \%$, specificity $93.6 \%$, positive predictive value $92.9 \%$ reported as. The purpose of invasive techniques used in patients with abnormal uterine bleeding is to detect benign intrauterine pathologies and especially to determine the diagnosis of endometrium cancer correctly. In recognition of normal and abnormal endometrial structure; sensitivity, specificity, negative predictive value and positive predictive values of $\mathrm{H} / \mathrm{S}$ is respectively was finded as $94.2 \%, 88.8 \%, 96.3 \%$ and 83.1\% (20). Although H/S can detect polyps with a high accuracy rate, it is not sufficient in detecting hyperplasia. In a study Lo et al. (21) showed that the sensitivity and positive predictive value of hysteroscopy without biopsy in diagnosing endometrial carcinoma were only 58.8\% and $20.8 \%$, respectively. In another study, the superiority of $\mathrm{H} / \mathrm{S}$ over $\mathrm{D} \& \mathrm{C}$ in recognizing endometrial hyperplasia and cancer was investigated. It is stated that, in the diagnosis of cancer and hyperplasia the gold standard is $\mathrm{D} \& \mathrm{C}$ but $\mathrm{H} / \mathrm{S}$ is more sensitive in detecting polyps and fibroids (16).

According to the study of Fukuda et al. (22), as a method hysteroscopy in determining endometrial pathologies has a sensitivity of $90 \%$, specificity of $82 \%$ was find. The sensitivity is $95 \%$ and specificity is $92 \%$ in determination of submucous fibroids, also in determing endometrial hyperplasia it was mentioned that the sensitivity is $97 \%$ and specificity $100 \%$ (22). Since the sensitivity of hysteroscopy in endometrial hyperplasia is very low, taking biopsy from endometrium is required. Vanderley 
et al. in the study where they compared ultrasonography and hysteroscopy in the evaluation of endometrial lesions; 191 patients were included in the study and although the accuracy rate of hysteroscopy in the evaluation of endometrial pathologies was above 90\%, TVUSG was $65.9 \%$ in endometrial polyps, $71.9 \%$ in myomas and in endometrial hyperplasia, it has an accuracy rate of $63.2 \%$ (23). According to our study, the effectiveness of hysteroscopy in evaluating endometrial pathologies; sensitivity 100\%, specificity 90\%, PPD 95.24\%, NPD $100 \%$ was determined as. In endometrial polyps; sensitivity $100 \%$, specificity $93.75 \%$, in submucous myomas; sensitivity $100 \%$, specificity $100 \%$ was found as. In endometrial hyperplasia,it is determined that sensitivity is $80 \%$, specificity is $100 \%$. The results were found to be similar to the literature.

\section{CONCLUSION}

Abnormal uterine bleeding is one of the most common causes of gynecological complaints. In terms of presenting treatment options to the patient, careful diagnosis of uterine cavity pathologies are necessary. According to the results of our study, for diagnosis; firstly an inexpensive and simple method should be chosen, later complicated and expensive methods must be tried. Hysteroscopy is the most reliable method in diagnosis of endometrial pathologies, is also the gold standard in diagnosis-treatment.

\section{ETHICAL DECLARATIONS}

Ethics Committee Approval: The study was approved by İstanbul Bakırköy Dr. Sadi Konuk Education and Research Hospital Ethics Committee (date: June 01, 2008; Approval number: 303).

Informed Consent: Written informed consent was obtained from all participants who participated in this study.

Referee Evaluation Process: Externally peer-reviewed.

Conflict of Interest Statement: The authors have no conflicts of interest to declare.

Financial Disclosure: The authors declared that this study has received no financial support.

Author Contributions: All of the authors declare that they have all participated in the design, execution, and analysis of the paper, and that they have approved the final version.

\section{REFERENCES}

1. FIGO classification system (PALM-COEIN) for causes of abnormal uterine bleeding in nongravid women of reproductiveage. FIGO Working Group on Menstrual Disorders. Munro MG, Critchley HO, Broder MS, Fraser IS. Int J Gynaecol Obstet 2011; 113: 3-13.

2. Hillard PJA. Benign diseases of the female reproductive tract: symptoms and signs. In: Berek JS, ed. Novaks Gynecology. 13th ed. Philadelphia: Lippincott Williams Wilkins; 2002. p.351-420.

3. Stovall T, Soloman S, Ling F. Endometrial sampling prior to hysterectomy. Obstet Gynecol 1989; 73: 405-9.

4. Cacciatore B, Ramsay T, Lehtovirta P, Ylöstalo P. Transvaginal sonography and hysteroscopy in postmenopausal bleeding. Acta Obstet Gynecol Scand 1994; 73: 413-16.

5. Oral Ö, Kayabaşoğlu F. Operatif Histeroskopi. Histeroskopi: Klinik uygulamalar ve güncel yaklaşımlar. Özay Oral, Furkan Kayabaşoğlu. İstanbul, Türkiye: İstanbul Tip Kitabevi; 2010.s: 6179.

6. Wolman I, Groutz A, Gordon D, Kupfermine MJ, Lessing JB, Jaffa AJ. Timing of sonohysterography in menstruating women. Gynecol Obstet Invest 1999; 48: 254-8.

7. Parsons AK, Cullinan JA, Goldstein SR, Fleicher AC. Sonohysterography, sonosalpingography, and sonohysterosalpingography; a map of normal and abnormal findings. In: Sonography in obstetrics and gynecology: principle and practice. Fleicher AC, eds. fifth edition. Tenesse 1996: Appleton\&Lange

8. Akyol A. Obezite ve kadın üreme sağlığı. Firat Med J 2018; 23: 48-53.

9. Ward KK, Roncancio AM, Shah NR, et al. The risk of uterine malignancy is linearly associated with body mass index in a cohort of US women. Am J Obstet Gynecol 2013; 209: 579.e1-5.

10. Yang TY, Cairns BJ, Allen N, Sweetland S, Reeves GK, Beral V. Postmenopausal endometrial cancer risk and body size in early life and middle age: Prospective cohort study. Br J Cancer 2012; 107: 169-75.

11. Jeong $\mathrm{NH}$, Lee JM, Lee JK, et al. Role of body mass index as a risk and prognostic factor of endometrioid uterine cancer in Korean women. Gynecol Oncol 2010; 24-8.

12. World Cancer Research Fund/American Institute for Cancer Research. Continuous Update Project Report. Food, Nutrition, Physical Activity, and the Prevention of Endometrial Cancer. 2013. (Erișim tarihi: 16.04.2020 https://www.wcrf.org/sites/ default/files/Endometrial-Cancer-2013-Report.pdf.)

13. Munro MG, Critchley HOD, Fraser IS. The two FIGO systems for normal and abnormal uterine bleeding symptoms and classification of causes of abnormal uterine bleeding in the reproductive years: 2018 revisions. Int J Gynecol Obstet 2018; 143: 393-408.

14.de Vries LD, Dijkhuizen FP, Mol BW, et al. Comparison oftransvaginal sonography, saline infusion sonography, and hysteroscopy in premenopausal women with abnormal uterine bleeding. J Clinl.Iltrasound 2000; 28: 217-23.

15.Dijkhuizen FP, Brolmann HA, Potters AE, et al. The accuracy oftvusg in the diagnosis of endometrial abnormalities. Obstet Gynecol 1996; 87: 345-9.

16. Dijkhuizen FP, de Vries LD, Mol BW et al. Comparison of transvaginal ultrasonography and saline infusion sonography for the detection of intraeavitary abnormalities in premenopausal women. Ultrasound Obstet Gynecol 2000; 15: 372-6.

17. Williams CD, Mashburn PB. A prospeetive study oftransvaginal hydrosonography in the evaluation of abnormal uterine bleeding. Am J Obstet Gynecol 1993; 179: 292-4. 
18. Ahmet K, Erdin İ, Hakan KE, Can T, Figen T. Anormal uterin kanamalı kadınların değerlendirilmesinde, TVUSG, HSG ve endometrial biyopsinin karşılaştırılması. TJOD 2005; 2: 327-31.

19. Garutti G, Sambrurii I, Cellarii F, et al. Hysteroscopy and transvaginal ultrasonography in postmenopausal women with uterine bleeding. Int J Gynecol Obstet 1999; 65: 25-33.

20.Garuti G, Sambruni I, Colonnelli M, et al. Accuracy of hysteroseopy in predicting histopathology of endometrium in 1500 women. J Am Assoe Gyneeol Laparosc 2001; 8: 207-13.

21.Lo KWK, Yuen PM.The role of outpatient diagnostic hysteroseopy in identifying anatomie pathologyand histopathology in the endometrial eavity. J Am Assoc Gynecol Laparoscopist 2000; 7: 381-5.

22. Ben-Yehuda OM, Kim YB, Leuchter RS. Does hysteroscopy improve upon the sensitivity of dilatation and curettage in the diagnosis of endometrial hyperplasia or carcinoma?. Gynecol Oncol 1998; 68: 4-7.

23. Fukuda M, Shimizu T, Fukuda $K$, et al. Transvaginal hysterosonography for differential diagnosis between submucous and intramural myoma. Gynecol Obstet Invest 1999; 35: 236-9.

24. Wanderley M da S, Álvares MM, Vogt M de FB, et al. Accuracy of transvaginal ultrasonography, hysteroscopy and uterine curettage in evaluating endometrial pathologies. Rev Bras Ginecol E Obstetrícia 2016; 38: 506-11. 